\title{
Allogenic Mesenchymal Stem Cell Transplantation for Refractory Severe Pyoderma Gangrenosum
}

\section{Xi Yang, Dandan Wang, Jun Liang, Jinyun Chen, Xuebing Feng and Lingyun Sun*}

Department of Rheumatology and Immunology, The Affiliated Drum Tower Hospital of Nanjing University Medical School, Nanjing, China

\begin{abstract}
Background: Pyoderma Gangrenosum (PG) is a rare and an idiopathic, inflammatory ulcerative condition, and the treatment are empirical and based on small series or local experience. Mesenchymal stem cells (MSCs) have immunomodulatory and tissue-repairing effects in autoimmune diseases, thus may have a potential role in PG treatment.
\end{abstract}

Objectives: This study aimed to assess the efficacy of UC-MSC transplantation (UC-MSCT) for wounded skin in a refractory severe PG patient.

Methods: A 29-year-old male PG patient was recruited. UC-MSCs were prepared by the Stem Cell Center of Jiangsu Province (Beike Bio-Technology). The patient underwent two times of UC-MSCT on June $13^{\text {th }}, 2012$ and June $27^{\text {th }}, 2012$. The protocol was approved by our Ethics Committee and signed informed consent was obtained from the patient.

Results: The PG patient presented with pustules over the lower limbs and was refractory to oral prednisolone (initially $60 \mathrm{mg}$ per day, tapered in 8 weekly steps to $5 \mathrm{mg}$ per day), pulse intravenous cyclophosphamide $(0.6 \mathrm{~g}$ per month for 6 months) and he also underwent two times unsuccessful of skin grafting for the lower extremity ulcers. There are no adverse events during the UC-MSCT treatment. After one week, he was free of intense pain and the exudation significantly reduced. Auto-skin grafting was given 4 weeks after UC-MSCT and the grafts came from his back and inner thigh. His ulcers significantly healed with complete resolution of pain 2 months after UC-MSCT. Maintenance therapy followed transplantation included prednisone $5 \mathrm{mg}$ per day and intravenous cyclophosphamide $0.6 \mathrm{~g}$ per month.

Conclusions: This is the first reported case of successful allogenic UC-MSCT for refractory severe PG. Although additional studies are needed to confirm this finding, we believe that UC-MSCT may be considered a therapeutic option for PG patients unresponsive to conventional treatments.

Keywords: Pyoderma Gangrenosum; Mesenchymal stem cells; Transplantation

\section{Case Report}

Pyoderma Gangrenosum (PG) is a rare and an idiopathic, inflammatory ulcerative condition, often associated with systemic autoimmune disease such as inflammatory bowel disease, rheumatoid arthritis, monoclonal gammapathy or hematological malignancies. Immunological factors and neutrophil dysfunction can be considered to be involved in the etiopathogenesis of PG [1]. PG lacks specific clinical, histopathologic or laboratory findings and is a diagnosis of exclusion. The standard treatment is long-term immunosuppression, often with high doses of corticosteroids, which are empirical and based on small series or local experience [2]. Mesenchymal stem cells (MSCs) have immunomodulatory and tissue-repairing effects in autoimmune diseases $[3,4]$. Previous animal researches demonstrated that MSCs may contribute to wounded skin, via processes involving MSCs differentiation various cell components of the skin, or prolonging skin graft survival in vivo [5,6]. Recent clinical findings also showed that umbilical cord-derived mesenchymal stem cell transplantation (UC-MSCT) was safe and effective in skin repair in a patient with drug-induced Stevens-Johnson syndrome [7,8]. UC-MSCs have weak immunogenicity for lack of the expression of the major histocompatibility complex (MHC) class II (HLA-DR) antigens, which make them free from immune resonance and the possible risk of graftversus-host disease (GVHD) in this therapy [9].

Here we report a successful treatment of refractory severe PG by UC-MSCT. Our patient, a 29-year-old man, presented with pustules over the lower limbs rapidly progressing to large, with central necrosis and undermined erythematous edges, for 5 years. Laboratory investigations, clinical manifestations and the histopathologic results were indicative of PG. The patient was refractory to oral prednisolone (initially $60 \mathrm{mg}$ per day, tapered in 8 weekly steps to $5 \mathrm{mg}$ per day) and pulse intravenous cyclophosphamide ( $0.6 \mathrm{~g}$ per month for 6 months). He also underwent two times of skin grafting (both autografts, in 2007 and 2010, respectively) for the lower extremity ulcers. The results were disappointing, and the ulcer edge was still reddish, swollen, and oozing a pus-like discharge, measuring $20 \mathrm{~cm} \times 10 \mathrm{~cm}$ (left) and $15 \mathrm{~cm} \times 15 \mathrm{~cm}$ (right) (Figure 1A).

The patient underwent two times of UC-MSCT on June $13^{\text {th }}, 2012$ and June $27^{\text {th }}, 2012$. Preparation of UC-MSCs is as follows: Umbilical cords (UCs) were obtained from local maternity hospitals after normal deliveries under informed consents. After having been minced into 1-2 $\mathrm{mm}^{3}$ fragments, UCs were incubated with $0.075 \%$ type II collagenase for $30 \mathrm{~min}$ and then $0.125 \%$ trypsin for a further $30 \mathrm{~min}$ with gentle agitation at $37^{\circ} \mathrm{C}$. The obtained cells were plated at a density of $1 \times 10^{6} /$

*Corresponding author: Lingyun Sun, MD, PhD, Department of Rheumatology and Immunology, The Affiliated Drum Tower Hospital of Nanjing University medical School, Nanjing, China, Tel: 8602583107038; E-mail: lingyunsun2012@163.com

Received April 14, 2014; Accepted June 20, 2014; Published June 22, 2014

Citation: Yang X, Wang D, Liang J, Chen J, Feng X, et al. (2014) Allogenic Mesenchymal Stem Cell Transplantation for Refractory Severe Pyoderma Gangrenosum. J Stem Cell Res Ther 4: 213. doi:10.4172/2157-7633.1000213

Copyright: (c) 2014 Yang X, et al. This is an open-access article distributed under the terms of the Creative Commons Attribution License, which permits unrestricted use, distribution, and reproduction in any medium, provided the original author and source are credited. 
Citation: Yang X, Wang D, Liang J, Chen J, Feng X, et al. (2014) Allogenic Mesenchymal Stem Cell Transplantation for Refractory Severe Pyoderma Gangrenosum. J Stem Cell Res Ther 4: 213. doi:10.4172/2157-7633.1000213

Page 2 of 2

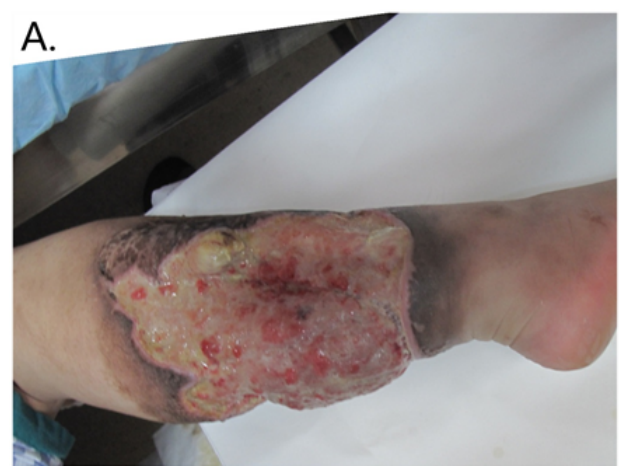

Figure 1A: Panel A Wound breakdown before UC-MSCT.

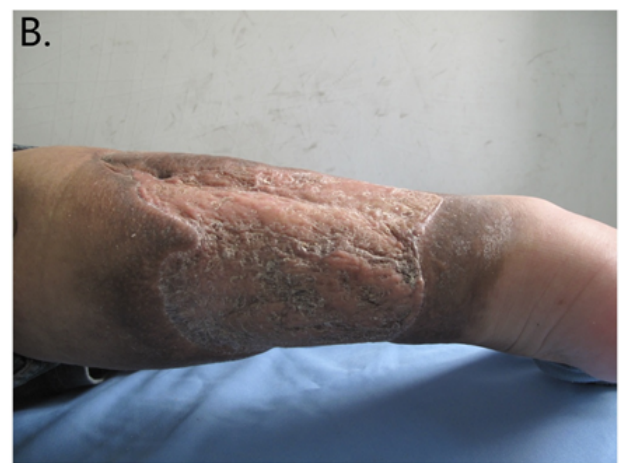

Figure 1B: Panel B Wound healing two months after UC-MSCT.

$\mathrm{cm}^{2}$ in noncoated T-25 or T-75 cell culture flasks. Growth medium consisted of Dulbecco's modified eagle's medium with low glucose and $5 \%$ fetal bovine serum. After 3 days of culture, nonadherent cells were removed and the medium was changed twice-weekly thereafter. Once $60-80 \%$ confluence had been reached, adherent cells were replated at a density of $1 \times-10^{4} / \mathrm{cm}^{2}$ in UC growth medium for expansion. After two passages, cells were harvested to confirm the expression of CD106, CD105, CD44 and CD29, but not CD34, CD14, CD19, HLA-DR and CD45. The capacity of MSCs to differentiate along adipogenic and osteogenic lineages was also assayed. The protocol was approved by our Ethics Committee and informed consent was signed from the patient. All the infused MSC were derived from passage 2 to passage 5, and $1 \times 10^{6}$ cells $/ \mathrm{kg}$ of body weight were given by intravenous infusion at each time, with no premedication such as steroids or antihistamines. He had no adverse events during treatment. After one week, he was free of intense pain and the exudation significantly reduced. Auto-skin grafting was given 4 weeks after UC-MSCT and the grafts came from his back and inner thigh. His ulcers significantly healed with complete resolution of pain 2 months after UC-MSCT (Figure 1B). Maintenance therapy followed transplantation included prednisone $5 \mathrm{mg}$ per day and intravenous cyclophosphamide $0.6 \mathrm{~g}$ per month.

This is the first reported case of successful allogenic UC-MSCT for refractory severe Pyoderma Gangrenosum. Although additional studies are needed to confirm this finding, we believe that UC-MSCT may be considered a therapeutic option in large area ulcerative PG patients unresponsive to conventional treatments.

\section{Acknowledgments}

This study was supported by grants from the National Natural Science Foundation of China (No. 81172847, 81273304).

\section{References}

1. Callen J P, Jackson J M (2007) Pyoderma gangrenosum: an update. Rheum Dis Clin North Am 33: 787-802. [PubMed]

2. Brooklyn T, Dunnill G, Probert C (2006) Diagnosis and treatment of pyoderma gangrenosum. Br Med J 333: 181-184. [PubMed]

3. Le Blanc K, Tammik C, Rosendahl K, Zetterberg E, Ringdén O (2003) HLA expression and immunologic properties of differentiated and undifferentiated mesenchymal stem cells. Exp Hematol 31: 890-896. [PubMed]

4. Sun $L$ (2010) Stem cell transplantation: progress in Asia. Lupus 19: 1468-1473. [PubMed]

5. Sasaki M, Abe R, Fujita Y, Ando S, Inokuma D, et al. (2008) Mesenchymal stem cells are recruited into wounded skin and contribute to wound repair by transdifferentiation into multiple skin cell type. J Immunol 180: 2581-2587. [PubMed]

6. Bartholomew A, Sturgeon C, Siatskas M, Ferrer K, Mclntosh K, et al. (2002) Mesenchymal stem cells suppress lymphocyte proliferation in vitro and prolong skin graft survival in vivo. Exp Hematol 30: 42-48. [PubMed]

7. Wang $\mathrm{D}$, Zhang H, Cao M, Tang Y, Liang J, et al. (2011) Efficacy of allogeneic mesenchymal stem cell transplantation in patients with drug-resistant polymyositis and dermatomyositis. Ann Rheum Dis 70: 1285-1288. [PubMed]

8. Li X, Wang D, Lu Z, Chen J, Zhang H, et al. (2013) Answer to 'Toxic epiderma necrolysis with failure of re-epithelialization. Could umbilical cord mesenchymal stem cell transplantation have a role? J Eur Acad Dermatol Venereol 27: 925. [PubMed]

9. Taghizadeh RR, Cetrulo KJ, Cetrulo CL (2011) Wharton's Jelly stem cells: Future clinical applications. Placenta 32: S311-S315. [PubMed] 